\title{
Relationship of Prostate Specific Antigen and Digital Rectal Examination in the Prediction of Prostate Cancer
}

Bhusan Raj Timilsina, ${ }^{1}$ Gaurav Devkota, ${ }^{2}$ Shweta Giri, ${ }^{1}$ Sulav Pradhan, ${ }^{1}$ Sudeep Raj KC ${ }^{3}$

${ }^{1}$ Dpartment of Surgery, College of Medical Sciences Teaching Hospital, Bharatpur, Chitwan, Nepal, ${ }^{2}$ School of Public Health, Patan Academy of Health Science, Lalitpur, Nepal, ${ }^{3}$ Dpartment of Urology, College of Medical Sciences Teaching Hospital, Bharatpur, Chitwan, Nepal.

\begin{abstract}
Background: Prostate cancer is one of the most common and leading cause of death among different genitourinary causes. However, screening of prostate cancer is limited to Digital Rectal Examination (DRE) and Prostate Specific Antigen (PSA) in Nepal. The aim of this study is to find out which modality is more helpful for the diagnosis of Prostate Cancer.
\end{abstract}

\begin{abstract}
Methods: A retrospective cross-sectional study was conducted in the department of Urology, College of Medical Sciences, Chitwan, Nepal. All patients included in this study were who presented to the OPD with Lower Urinary Tract Symptoms (LUTS). The patients were above the age of 40 with clinical suspicion prostate cancer based on either DRE or PSA.

Results: A total of 150 patients were enrolled from April 2019 to April 2020. Their mean \pm SD age was of $65.18 \pm 9.38$ years. The accuracy of the diagnostic test for DRE and PSA were cut off at 4 , PSA cut off range of 4 to 10, PSA cut off range of 10 to 30 and PSA cut off at 30 showed that all the screening indices were better for DRE (Sensitivity $=100 \%$, Specificity $=59.2 \%$, Diagnostic Accuracy $=62.2 \%$ ) than for PSA cut off at 4 (Sensitivity $=100 \%$, Specificity $=27.6 \%$, Diagnostic Accuracy=32.9\%). Among various cut off score or ranges for PSA, cut off score at 30 provided the best screening indices with Sensitivity of $66.7 \%$, Specificity of $97.4 \%$ and Diagnostic Accuracy of $95.1 \%$.
\end{abstract}

Conclusions: PSA has higher diagnostic accuracy then DRE.

Keywords: DRE; LUTS; Prostate cancer; PSA.

\section{INTRODUCTION}

Benign Prostatic Hyperplasia (BPH) originates in the transition zone and periurethal area. About 60$70 \%$ percent of carcinomas of the prostate originate in the peripheral zone, $10-20 \%$ in the transition zone and $5-10 \%$ in the central zone. ${ }^{1}$ In early 1905 , Hugh H. Young stated that Digital Rectal Examination (DRE) could identify prostatic cancer that heralds the first signs of cancer. For the next 75 years, this was the only screening test available, but an imperfect one. ${ }^{2}$ In the early 1980 s, clinicians reacted with optimism to initial studies using a Blood Protein, Prostate--Specific Antigen (PSA), as a screening test for this disease because of an increasing death rate and the poor diagnostic performance of the DRE. ${ }^{3}$ The DRE should be performed in every males after the of age 40 years and anyone who present for an urological evaluation of prostate cancer which is the second most common cause of can correlated deaths in patients after the age of 55years and the most common cause of cancer related deaths in men older than 70 years.
Most of the prostate cancer can be detected in an early curable stage by DRE. ${ }^{3}$ DRE is important in men to assess the prostate for size, nodularity, and/ or tenderness. Normally, the prostate is about the size of a chestnut and has a consistency similar to that of the contracted eminence of the thumb. ${ }^{4}$

Early diagnosis of prostate cancer is hindered by the lack of symptoms therefore, an early detection requires an effective test which also needs to be simple, safe and inexpensive. The DRE is notoriously imprecise. It lacks sufficient sensitivity and is more likely to detect disease when it has advanced. Only $30 \%$ to $40 \%$ of cancers [are] detected by DRE and can be expected to be an organ confined. When prostate cancer is detected by PSA, a majority of tumors are organ confined and clinically significant. ${ }^{5}$ Due to the increased risk of prostate cancer among men with abnormalities on DRE and the simplicity of the examination, most urologists use PSA and DRE together for prostate cancer detection. ${ }^{6}$ The aim of

Correspondence: Dr. Bhusan Raj Timilisina, Department of Surgery, College of Medical Sciences, Bharatpur, Chitwan, Nepal. Email: bhusantimilsina827@gmail.com. Phone: +977-9851130744. Article received: 202003-20. Article accepted: 2020-06-15. 
this study is to correlate prostate specific antigen, digital rectal examination and prostate biopsy in the diagnosis of patient with suspected carcinoma of prostate.

\section{METHODS}

A retrospective cross-sectional study was conducted in the department of Urology ,College of Medical Sciences- Teaching Hospital, Chitwan, Nepal after the approval from Institutional Review Committee: ref no 2020- 049. Data was collected from the outpatient department where LUTS, DRE, PSA, prostate biopsy was included. A one-year data was collected from February 2019 to February 2020. A total number of 150 cases were carried out which was taken as the sample size. The other variables found during these data collection were Age, USG size of prostate gland, back pain, storage symptom, voiding symptoms, use of 5-alpha reductase, history of instrumentation and history of prostate surgery. This hospital has established a protocol in which the patients above the age of 40 having Benign Enlargement of Prostate (BEP) and Lower Urinary Tract Symptoms (LUTS) undergo routine screening for prostate cancer. For the screening process, blood sample is collected prior to DRE and PSA. PSA is analysed with CLIA methodology and using Snibe maglumi 2000 machine which was made in china. A level [of] $>4 \mathrm{ng} / \mathrm{dl}$ is considered abnormal.

Then, the patient undergoes DRE. Findings: Prostate hard on consistency, obliteration of medina sulcus, induration to rectal mucosa and nodular were considered suspicious of malignancy. Those individuals who have high PSA levels and strong clinical suspicion of malignancy will be subjected to trucut biopsy. Prophylactic antibiotic like levofloxacin and ornidazole was given a day prior to tactile transrectal prostate biopsy. Exclusion to biopsy were patient having UTI, bleeding coagulopathies. Patients with infection and coagulopathy were not subjected to biopsy either. The collected data's were then entered into the Microsoft Excel-2007 and later imported to SPSS v 11.5 for statistical analysis to carry out descriptive statistics, mean, standard deviation, proportion and percentage. The screening indices for DRE and different cut-off of PSA were calculated using EZR version 1.38. For inferential statistics, exact logistic regression was used and the $p$ value $\leq 0.05$ was considered statistically significant.

\section{RESULTS}

One hundred and fifty cases studied showed a mean \pm SD age of $65.18 \pm 9.38$ years, mean serum PSA of $6.07 \pm 12.32$ and mean weight of prostate on USG as $52.89 \pm 17.19$. Among them, only those patients with suspected malignancy based on DRE or PSA level ( $>4 \mathrm{ng} / \mathrm{dl})$ or both were subjected to biopsy. A number of 82 patients underwent prostate biopsy, with mean \pm SD age of $66.28 \pm 8.33$ years, mean \pm SD serum PSA of $9.99 \pm 15.61$ and mean \pm SD weight of prostate on USG as $55.54 \pm 19.52$. The descriptive analyses of all the categorical variables used in the study are provided in Table 1 . Six out of 82 patients i.e. $7.32 \%$ (C.I. $2.7 \%$ to $15.2 \%$ ) were diagnosed to have adenocarcinoma on prostate biopsy (Table 1).

\begin{tabular}{|c|c|c|}
\hline $\begin{array}{l}\text { Table 1. Frequency } \\
\text { categorical variables }\end{array}$ & $\begin{array}{l}\text { percent } \\
\text { n the stud }\end{array}$ & $\begin{array}{l}\text { stribution } \\
(n=82)\end{array}$ \\
\hline Variable & Frequency & Percentage \\
\hline Backpain & & \\
\hline Absent & 74 & 90.24 \\
\hline Present & 8 & 9.76 \\
\hline Storage symptoms & & \\
\hline Absent & 38 & 46.34 \\
\hline Present & 44 & 53.66 \\
\hline Voiding symptoms & & \\
\hline No & 30 & 36.59 \\
\hline Yes & 52 & 63.41 \\
\hline Finasteride use & & \\
\hline No & 74 & 90.24 \\
\hline Yes & 8 & 9.76 \\
\hline Past instrumentation & & \\
\hline No & 80 & 97.56 \\
\hline Yes & 2 & 2.44 \\
\hline Past prostrate surgery & & \\
\hline No & 81 & 98.78 \\
\hline Yes & 1 & 1.22 \\
\hline DRE findings & & \\
\hline Bening & 45 & 54.88 \\
\hline Suspected malignancy & 37 & 45.12 \\
\hline DRE Prostate Grade & & \\
\hline Grade 1 & 2 & 2.44 \\
\hline Grade 2 & 24 & 29.27 \\
\hline Grade 3 & 44 & 53.66 \\
\hline Grade 4 & 12 & 14.63 \\
\hline PSA cut off at 4 & & \\
\hline Less than 4 & 21 & 25.61 \\
\hline More than or equal to 4 & 61 & 74.39 \\
\hline PSA cut off at 30 & & \\
\hline Less than 30 & 76 & 92.68 \\
\hline More than or equal to 30 & 6 & 7.32 \\
\hline Adenocarcinoma in bio & & \\
\hline No & 76 & 92.68 \\
\hline Yes & 6 & 7.32 \\
\hline
\end{tabular}

Following table illustrates the screening indices calculated for DRE, PSA cut off at 4, PSA cut off range of 4 to 10, PSA cut off range of 10 to 30 and PSA cut off at 30 which shows that all the screening indices were better for DRE (Sensitivity $=100 \%$, Specificity $=59.2 \%$, Diagnostic Accuracy $=62.2 \%$ ) than for PSA cut off at 4 (Sensitivity $=100 \%$, Specificity $=27.6 \%$, Diagnostic Accuracy $=32.9 \%$ ). Among various cut off score or ranges for PSA, cut off score at 30 provided the best screening indices with Sensitivity of $66.7 \%$, 
Specificity of $97.4 \%$ and Diagnostic Accuracy of 95.1\% (Table 2).

Following table provides the screening indices for combination of suspected malignancy on DRE and back pain (OR 13.231, CI 1.416-128.327,p<0.05), Suspected Malignancy on DRE (OR 11.322, CI $1.560-\infty, \mathrm{p}<0.05$ ) and PSA more than 30 (OR $60.775, \quad$ CI $5.537-1102.264, \mathrm{p}<0.001) \quad$ had significant association with adenocarcinoma.

\begin{tabular}{|c|c|c|c|c|c|}
\hline Screening Indices & DRE & PSA (cut off at 4) & $\begin{array}{l}\text { PSA (cut off range } \\
4 \text { to 10) }\end{array}$ & $\begin{array}{l}\text { PSA (cut off range } \\
10 \text { to 30) }\end{array}$ & PSA (cut off at 30) \\
\hline $\begin{array}{l}\text { Apparent Preva- } \\
\text { lence }\end{array}$ & $\begin{array}{l}0.451(0.341- \\
0.565)\end{array}$ & $0.744(0.636-0.834)$ & $0.573(0.459-0.682)$ & $0.098(0.043-0.183)$ & $0.073(0.027-0.152)$ \\
\hline True Prevalence & $\begin{array}{l}0.073(0.027- \\
0.152)\end{array}$ & $0.073(0$. & 0.073 & 0.073 & $0.073(0$. \\
\hline Sensitivity & $1.00(0.421-1.00)$ & $1.00(0.421-1.00)$ & $0.00(0.00-0.579)$ & $0.333(0.043-0.777)$ & $0.667(0.223-0.957)$ \\
\hline Specificity & $\begin{array}{l}0.592(0.473- \\
0.704)\end{array}$ & $0.276(0.180-0.391)$ & $0.382(0.272-0.500)$ & $0.921(0.836-0.970)$ & $0.974(0.908-0.997)$ \\
\hline $\begin{array}{l}\text { Positive Predictive } \\
\text { Value }\end{array}$ & $\begin{array}{l}0.162(0.062- \\
0.320)\end{array}$ & $0.098(0.037-0.202)$ & $0.00(0.00-0.111)$ & $0.250(0.032-0.651)$ & $0.667(0.223-0.957)$ \\
\hline $\begin{array}{l}\text { Negative Predic- } \\
\text { tive Value }\end{array}$ & $1.00(0.885-1.00)$ & $1.00(0.772-1.00)$ & $0.829(0.664-0.934)$ & $0.946(0.867-0.985)$ & $0.974(0.908-0.997)$ \\
\hline $\begin{array}{l}\text { Diagnostic Accura- } \\
\text { cy }\end{array}$ & $\begin{array}{l}-0.622(0.508- \\
0.727)\end{array}$ & $0.329(0.229-0.442)$ & $0.354(0.251-0.467)$ & $0.878(0.787-0.940)$ & $0.951(0.880-0.987)$ \\
\hline $\begin{array}{l}\text { Likelihood ratio of } \\
\text { a positive test }\end{array}$ & $\begin{array}{l}2.452(1.870- \\
3.214)\end{array}$ & $1.382(1.203-1.588)$ & $0.00(0.00-\mathrm{NA})$ & $\begin{array}{l}4.222(1.076- \\
16.575)\end{array}$ & $\begin{array}{l}25.333(5.767- \\
111.284)\end{array}$ \\
\hline $\begin{array}{l}\text { Likelihood ratio of } \\
\text { a negative test }\end{array}$ & $0.00(0.00-\mathrm{NA})$ & $0.00(0.00-\mathrm{NA})$ & $2.621(1.968-3.489)$ & $0.724(0.409-1.279)$ & $0.342(0.110-1.062)$ \\
\hline
\end{tabular}

PSA cut offs at 4 and at 30 which shows that screening indices for suspected malignancy on DRE and PSA cut off at 4 was better than DRE or PSA cut off at 4 alone. Combination of suspected malignancy on DRE and PSA cut off at 30 showed same screening indices as PSA cut off at 30 alone (Table 3). Exact logistic regression was performed on dichotomous result of biopsy of prostate

\begin{tabular}{|c|c|c|}
\hline \multicolumn{3}{|c|}{$\begin{array}{l}\text { Table 3. Point estimates and } 95 \% \text { CI of screening } \\
\text { indices for combination of suspected malignancy on } \\
\text { DRE and different PSA cut offs (at } 4 \text { and } 30) \text {. }\end{array}$} \\
\hline Screening Indices & $\begin{array}{l}\text { Suspected malig- } \\
\text { nancy on DRE } \\
\text { and PSA cut off } \\
\text { at } 4\end{array}$ & $\begin{array}{l}\text { Suspected malig- } \\
\text { nancy on DRE and } \\
\text { PSA cut off at } 30\end{array}$ \\
\hline Apparent Prevalence & $\begin{array}{l}0.220(0.136- \\
0.325)\end{array}$ & $0.073(0.027-0.152)$ \\
\hline True Prevalence & $\begin{array}{l}0.073(0.027- \\
0.152)\end{array}$ & $0.073(0.027-0.152)$ \\
\hline Sensitivity & $1.00(0.421-1.00)$ & $0.667(0.223-0.957)$ \\
\hline Specificity & $\begin{array}{l}0.842(0.740- \\
0.916)\end{array}$ & $0.974(0.908-0.997)$ \\
\hline $\begin{array}{l}\text { Positive Predictive } \\
\text { Value }\end{array}$ & $\begin{array}{l}0.333(0.133- \\
0.590)\end{array}$ & $0.667(0.223-0.957)$ \\
\hline $\begin{array}{l}\text { Negative Predictive } \\
\text { Value }\end{array}$ & $1.00(0.917-1.00)$ & $0.974(0.908-0.997)$ \\
\hline Diagnostic Accuracy & $\begin{array}{l}0.854(0.758- \\
0.922)\end{array}$ & $0.951(0.880-0.987)$ \\
\hline $\begin{array}{l}\text { Likelihood ratio of a } \\
\text { positive test }\end{array}$ & $\begin{array}{l}6.333(3.768- \\
10.644)\end{array}$ & $\begin{array}{l}25.333(5.767- \\
111.284)\end{array}$ \\
\hline $\begin{array}{l}\text { Likelihood ratio of a } \\
\text { negative test }\end{array}$ & $0.00(0.00-\mathrm{NA})$ & $0.342(0.110-1.062)$ \\
\hline
\end{tabular}

(adenocarcinoma present 1 or absent 0 ) to identify the odds of presence of adenocarcinoma for different variables. Variate exact logistic regression showed that only Serum PSA [Odds Ratio (OR) 1.094, CI 1.042-1.162,p<0.001], Presence of
Among these four significant variables, PSA cut off at 30 was discarded from multivariate exact logistic regression due to multicollinearity. The $p$-value for the multivariate model was less than 0.05 and thus the model was a fit. On multivariate analysis, serum PSA showed significant adjusted odds ratio (AOR $=1.067$, CI 1.009-1.172, $\mathrm{p}<0.05$ ) which shows that the odd of getting adenocarcinoma increases by 1.067 times with one unit increase in PSA. Adjusted OR for presence of the backpain and suspected malignancy findings on DRE could not be calculated as there was no convergence in conditional exact logistic regression and these variables got degenerated (Table 4).

\section{DISCUSSION}

The introduction of prostate-specific antigen (PSA) testing has revolutionized the diagnosis of patients with prostate cancer. PSA lacks specificity in differentiating between benign prostatic hyperplasia $(\mathrm{BPH})$ and prostate cancer. The inability of PSA to differentiate clearly $\mathrm{BPH}$ and prostate cancer, especially when the serum PSA value is only slightly elevated, can result in needless biopsies or additional testing. ${ }^{7}$ There are many studies which suggest that the normal range of PSA needs to be increased and should range between 7.5-10 ng per millilitre. ${ }^{8,9}$ Biomarkers, like PCA3 which is detected in the urine of patient with carcinoma of prostate, is more specific then PSA but is not widely used. ${ }^{10}$ Newer biomarkers like human kallikrein 11 (hK11) have higher sensitivity and specificity but these biomarkers are yet to establish 
Timilsina et al. Relationship of Prostate Specific Antigen and Digital Rectal Examination..

\begin{tabular}{|c|c|c|c|c|}
\hline Variable & OR (C.I.) & p-value & $\overline{A O R}$ & p-value \\
\hline Age & $1.006(0.910-1.120)$ & 0.944 & & \\
\hline Weight on USG & $0.992(0.942-1.035)$ & 0.813 & & \\
\hline Serum PSA & $1.094(1.042-1.162)$ & $<0.001$ & $1.067(1.009-1.172)$ & 0.0169 \\
\hline \multicolumn{5}{|l|}{ Backpain } \\
\hline Absent & Reference & & & \\
\hline Present & $13.231(1.416-128.327)$ & 0.022 & $1.0(0.00-\infty)$ & \\
\hline \multicolumn{5}{|l|}{ Storage symptoms } \\
\hline Absent & Reference & & & \\
\hline Present & $0.855(0.108-6.800)$ & 1 & & \\
\hline \multicolumn{5}{|l|}{ Voiding symptoms } \\
\hline Absent & Reference & & & \\
\hline Present & $1.165(0.155-13.649)$ & 1 & & \\
\hline \multicolumn{5}{|l|}{ Finasteride use* } \\
\hline No & Reference & & & \\
\hline Yes & $1.097(0.0-8.687)$ & 1 & & \\
\hline \multicolumn{5}{|l|}{ Past instrumentation* } \\
\hline No & Reference & & & \\
\hline Yes & $5.319(0.0-72.213)$ & 1 & & \\
\hline \multicolumn{5}{|l|}{ Past prostrate surgery* } \\
\hline No & Reference & & & \\
\hline Yes & $12.667(0.0-494)$ & 1 & & \\
\hline \multicolumn{5}{|l|}{ DRE findings* } \\
\hline Benign & Reference & & & \\
\hline Suspected Malignancy & $11.322(1.560-\infty)$ & 0.013 & $1.0(0.00-\infty)$ & \\
\hline \multicolumn{5}{|l|}{ DRE Prostate Grade } \\
\hline All subgroups (combined) & $1.533(0.400-6.510)$ & 0.693 & & \\
\hline \multicolumn{5}{|l|}{ PSA cut off at $4 *$} \\
\hline Less than 4 & Reference & & & \\
\hline More than or equal to 4 & $3.009(0.409-\infty)$ & 0.317 & & \\
\hline \multicolumn{5}{|l|}{ PSA cut off at $30 *$} \\
\hline Less than 30 & Reference & & & \\
\hline More than or equal to 30 & $60.775(5.537-1102.264)$ & $<0.001$ & & \\
\hline
\end{tabular}

themselves as a prostate specific. Before the era of PSA, prostate cancer was diagnosed with the help of DRE. DRE has subjective variations and often diagnose when the disease has already spread. ${ }^{11}$ When a patient comes to the OPD with a history of LUTS, he should be initially evaluated with history and clinical examination and subsequently be subjected to DRE and screening PSA level. Serum PSA is considered as one of the best screening tool.

In a study conducted in 2009 , Imam et al showed the rate of prostate cancer detection to be $25.7 \%$ for PSA $>4 \mathrm{ng} / \mathrm{ml}, 13.31 \%$ for abnormal (positive) finding of DRE, and $27.8 \%$ for combination of the positive DRE and PSA $>4 \mathrm{ng} / \mathrm{ml}^{12}$ In our study, diagnostic accuracy of DRE was found to be 0.622 and that of PSA was found to be 0.32 where the cut off value is $4 \mathrm{ng} / \mathrm{ml}$ and 0.951 where the cut off value is $30 \mathrm{ng} / \mathrm{ml}$. Positive predictive value was found to be 0.162 and negative predictive value was found to be 1.00 in DRE. Whereas for PSA, PPV and NPV is 0.98 and 1.00 where cut off value is less than $4 \mathrm{ng} / \mathrm{ml}$ and where cut of value is taken as $30 \mathrm{ng} / \mathrm{ml} \mathrm{PPV}$ and NPV is 0.667 and 0.974 respectively. In 2013 Belbase et al. studied total of
1521 patient which included both general population and prostate patients who presented to OPD the specificity of DRE was $66.0 \%$ with a sensitivity of $90.9 \%$ and a positive predictive value of $38.5 \%{ }^{13}$ The sensitivity of PSA more than $4 \mathrm{ng} /$ $\mathrm{ml}$ in detecting carcinoma prostate was $100 \%$ and the positive predictive value for serum PSA was $19.0 \% .{ }^{13}$ This study has a better positive predictive value of in PSA and less positive predictive value in DRE.

Higashihara et al., in 1996 stated a positive predictive value of 10.60 , sensitivity of 69.20 and specificity of 26.20 for DRE and positive predictive value of 24.00 , sensitivity of 92.30 and a specificity of 63.10 for PSA. There are several other studies with similar results. Our study showed that there is increase in sensitivity, specificity, PPV, NPV and diagnostic accuracy more with PSA than with DRE, as the level of PSA increases. This study does have some limitations thus, must be interpreted with a degree of caution. This is a single center study with a comparatively smaller sample size and its results cannot be generalized. Transrectal ultrasound (TRUS) guided prostate biopsy is the standard 
method but due to limitations, we performed a tactile transrectal prostate biopsy, which may fail to detect small malignant growths in the prostate. The use of size of trucut biopsy needle is not there in the data, further more the use of small size of biopsy needle may lead to failure of detection of prostate cancer. The MRI records of the respective patients could not be found which would also aid as a diagnostic tool; the use of reagent for PSA could also play a role. We could not determine or record the method of urine sample collection. Incorrect collection of the urine sample could have affected the results.

\section{Recommendation}

Our study showed the higher PSA level had more diagnostic accuracy in prostate cancer but there are many studies that suggest PSA greater than $4 \mathrm{ng} / \mathrm{dl}$ is highly sensitive and is specific for the diagnosis of a prostate cancer. The use of TRUS and MRI guided prostate biopsy with broader needle and standard way of collecting urinary sample will definitely improve the sensitivity and specificity of PSA for detection of prostate cancer. We need further study after correcting our inefficacy to establish accurate relationship between PSA and prostate cancer.

\section{CONCLUSION}

PSA is a very useful screening tool for the diagnosis of a prostate cancer. Screenings of prostate cancer that are missed during DRE are also detected with the help of PSA.

Conflict of Interest: None

\section{REFERENCES}

1. McNeal JE, Redwine EA, Freiha FS, TA. S. Zonal distribution of prostatic adenocarcinoma. Correlation with histologic pattern and direction of spread. The American journal of surgical pathology. 1988 Dec;12(12):897-906.

2. Brawley OW, DP. A. Thompson IM. Screening for prostate cancer. CA Cancer J Clin. 2009;59(4):26473.

3. Catalona WJ, Smith DS, Ratliff TL, Dodds KM, Coplen DE, Yuan JJ, et al. Measurement of prostatespecific antigen in serum as a screening test for prostate cancer. New England Journal of Medicine. 1991 Apr;324(17):1156-61.

4. Crawford ED, DeAntoni EP, Etzioni R, Schaefer VC, Olson RM, Ross CA, et al. Serum prostatespecific antigen and digital rectal examination for early detection of prostate cancer in a national community-based program. Urology. 1996 Jun;47 (6):863-9.

5. GS G. Evaluation of the urologic patient: history, physical examination, and urinalysis. Campbell's urology. 2002:83-110.

6. Schröder FH, Kruger AB, Rietbergen J, Kranse R, Maas PV, P. B. Evaluation of the digital rectal examination as a screening test for prostate cancer. Journal of the National Cancer Institute. 1998 Dec;90(23):1817-23.

7. Ferro MA, Barnes I, Roberts JB, PJ S. Tumour markers in prostatic carcinoma. A comparison of prostate-specific antigen with acid phosphatase.
British journal of urology. 1987 Jul;60(1):69-73.

8. Kuriyama M, Wang MC, Lee CL, Killian CS, Papsidero LD, Inaji $\mathrm{H}$, et al. Multiple marker evaluation in human prostate cancer with the use of tissue-specific antigens. Journal of the National Cancer Institute. 1982 Jan;68(1):99-105.

9. Pontes JE, Chu TM, Slack N, Karr J, GP M. Serum prostatic antigen measurement in localized prostatic cancer: correlation with clinical course. The Journal of urology. $1992 \mathrm{Dec} ; 128(6): 1216-8$.

10. Laxman B, Morris DS, Yu J, Siddiqui J, Cao J, Mehra R, et al. A first-generation multiplex biomarker analysis of urine for the early detection of prostate cancer. Cancer research. 2008 Feb;68 (3):645-9.

11. Thompson IM, Ernst JJ, Gangai MP, CR. S. Adenocarcinoma of the prostate: results of routine urological screening. The Journal of urology. 1984 Oct;132(4):69--2.

12. Mohammed El Imam MA, Higazi NZ, Abuidris DO, Idris AA, Khalid KE, Omran M, et al. Prostate Specific Antigen versus Digital Rectal Examination as screening for ca prostate in Sudanese patients. Sudanese Journal of Public Health. 2009;4(2):27881.

13. Belbase NP, Agrawal CS, Pokharel PK, Agrawal S, Lamsal M, VC. S. Prostate cancer screening in a healthy population cohort in eastern Nepal: an explanatory trial study. Asian Pac J Cancer Prev. 2013 Jan 14(5):2835-8.

Citation: Timilsina BR, Devkota G, Giri S, Pradhan S, KC SR. Relationship of Prostate Specific Antigen and Digital Rectal Examination in the Prediction of Prostate Cancer. JCMS Nepal. 2020; 16(2):83-7. 